\title{
Author Correction: Hepatic Impairment Physiologically Based Pharmacokinetic Model Development: Current Challenges
}

\author{
Agnes Nuo Han ${ }^{1}$ - Beatrice Rae Han ${ }^{2} \cdot$ Tao Zhang $^{3} \cdot$ Tycho Heimbach $^{3,4}$
}

Published online: 26 October 2021

C) Springer Nature Switzerland AG 2021

\section{Author Correction: Current Pharmacology Reports https://doi.org/10.1007/s40495-021-00266-5}

The original version of this article unfortunately contained a mistake. Equal contribution note and Tables 1 and 2 are missing in the original article. Tables 1 and 2 are shown here.

The original article has been corrected.

Publisher's Note Springer Nature remains neutral with regard to jurisdictional claims in published maps and institutional affiliations.

Beatrice Han and Agnes Han contributed equally.

The original article can be found online at https://doi.org/10.1007/ s40495-021-00266-5.

Tycho Heimbach

Tycho.Heimbach@Merck.com

1 Washington University in St. Louis, St. Louis, MO 63130, USA

2 University of Pennsylvania, Philadelphia, PA 19104, USA

3 School of Pharmacy, Husson University, Bangor, ME 04401, USA

4 MRL - Sterile \& Specialty Products Group,

Biopharmaceutics Merck \& Co., Inc., 126 E Lincoln Avenue

- RY80B, 1416E, Rahway, NJ 07065, USA 


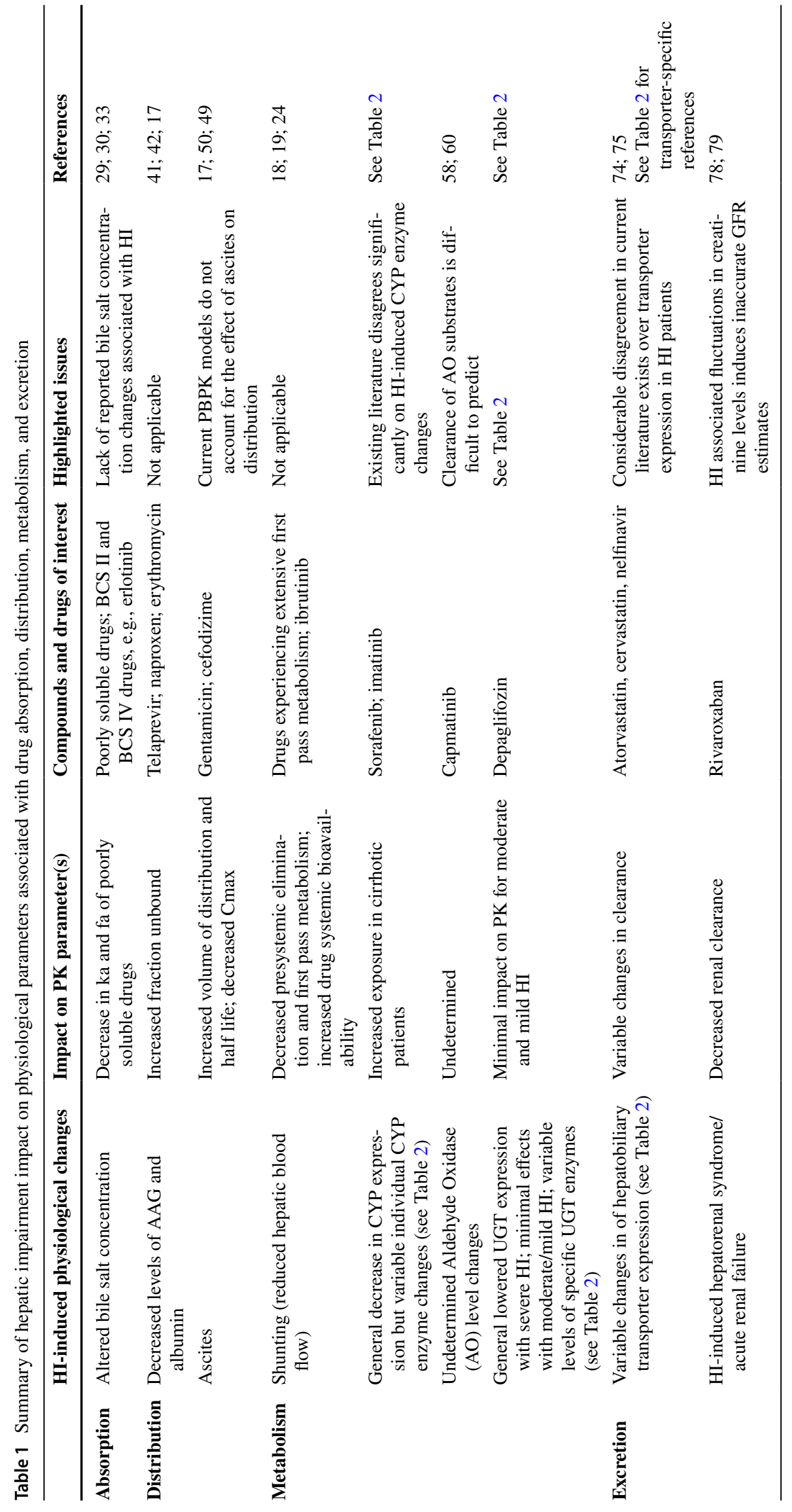


Table 2 Summary of HI-induced changes in drug-metabolizing enzymes and drug transporters

\begin{tabular}{|c|c|c|c|c|}
\hline Metabolism & Enzyme & Disease stage & $\begin{array}{l}\text { Expression level change with HI relative to healthy volun- } \\
\text { teer }\end{array}$ & References \\
\hline & CYP3A4 & General liver cirrhosis & Decrease & $13 ; 17$ \\
\hline & CYP1A2 & $\begin{array}{l}\text { General liver cirrhosis } \\
\text { NAFLD }\end{array}$ & $\begin{array}{l}\text { Decrease } \\
\text { Decrease }\end{array}$ & $\begin{array}{l}17 \\
54\end{array}$ \\
\hline & CYP2A6 & $\begin{array}{l}\text { General liver cirrhosis } \\
\text { NAFLD }\end{array}$ & $\begin{array}{l}\text { Decrease } \\
\text { Increase }\end{array}$ & $\begin{array}{l}17 \\
54\end{array}$ \\
\hline & CYP2B6 & General liver cirrhosis & Decrease & 17 \\
\hline & CYP2C8 & $\begin{array}{l}\text { General liver cirrhosis } \\
\text { General liver cirrhosis }\end{array}$ & $\begin{array}{l}\text { Decrease } \\
\text { No change }\end{array}$ & $\begin{array}{l}17 \\
13\end{array}$ \\
\hline & CYP2C9 & $\begin{array}{l}\text { General liver cirrhosis } \\
\text { Alcoholic and HCV cirrhotic livers } \\
\text { General liver cirrhosis } \\
\text { NAFLD }\end{array}$ & $\begin{array}{l}\text { Decrease } \\
\text { Decrease } \\
\text { No change } \\
\text { Increase }\end{array}$ & $\begin{array}{l}17 \\
64 \\
13 \\
54\end{array}$ \\
\hline & CYP2C18 & General liver cirrhosis & Decrease & 17 \\
\hline & CYP2C19 & $\begin{array}{l}\text { General liver cirrhosis } \\
\text { NAFLD }\end{array}$ & $\begin{array}{l}\text { Decrease } \\
\text { Decrease }\end{array}$ & $\begin{array}{l}17 \\
54\end{array}$ \\
\hline & CYP2D6 & $\begin{array}{l}\text { General liver cirrhosis } \\
\text { NAFLD }\end{array}$ & $\begin{array}{l}\text { Decrease } \\
\text { Decrease }\end{array}$ & $\begin{array}{l}17 \\
54\end{array}$ \\
\hline & CYP2E1 & $\begin{array}{l}\text { General liver cirrhosis } \\
\text { NAFLD }\end{array}$ & $\begin{array}{l}\text { Decrease } \\
\text { Decrease }\end{array}$ & $\begin{array}{l}17 \\
54\end{array}$ \\
\hline & UGT & & & \\
\hline & UGT1A6 & Alcoholic cirrhosis and HCV cirrhosis & Decrease to less than $25 \%$ & 64 \\
\hline & UGT1A4 & Alcoholic cirrhosis and HCV cirrhosis & $\begin{array}{l}\text { Decrease to less than } 25 \% \text {; Decrease was larger for alcoholic } \\
\text { cirrhosis vs. HCV cirrhosis }\end{array}$ & 64 \\
\hline & UGT2B7 & Alcoholic cirrhosis and HCV cirrhosis & Decrease to less than $25 \%$ & 64 \\
\hline & UGT1A9 & General liver cirrhosis & Decrease & 65 \\
\hline & Other enzy & mes & & \\
\hline & ADH1A & Alcoholic cirrhosis & Decrease to less than $25 \%$ & 64 \\
\hline & ADH1B & Alcoholic cirrhosis & Decrease to less than $25 \%$ & 64 \\
\hline & AOX1 & Alcoholic cirrhosis & Decrease to less than $25 \%$ & 64 \\
\hline & CES1A2 & Alcoholic cirrhosis & Decrease to less than $25 \%$ & 64 \\
\hline
\end{tabular}


Table 2 (continued)

Metabolism Enzyme Disease stage

Expression level change with HI relative to healthy volun-

References teer

\begin{tabular}{|c|c|c|c|c|}
\hline \multirow[t]{13}{*}{ Excretion } & \multicolumn{4}{|c|}{ Transporters } \\
\hline & OCT1 & $\begin{array}{l}\text { Hep C cirrhosis } \\
\text { CPC }\end{array}$ & $\begin{array}{l}38 \% \text { decreased expression } \\
65 \% \text { decreased expression }\end{array}$ & $\begin{array}{l}12 \\
73\end{array}$ \\
\hline & OATP2B1 & $\begin{array}{l}\text { HCV } \\
\text { NASH } \\
\text { PBC } \\
\text { Alcoholic cirrhosis } \\
\text { CPC }\end{array}$ & $\begin{array}{l}\text { Decreased } \\
\text { Increased } \\
\text { Decreased } \\
\text { No change } \\
63 \% \text { decreased expression }\end{array}$ & $\begin{array}{l}75 \\
75 \\
76 \\
12 \\
73\end{array}$ \\
\hline & OATP1B3 & Hep C cirrhosis & Decreased & 12 \\
\hline & MRP2 & $\begin{array}{l}\text { HCV } \\
\text { NASH } \\
\text { PBC } \\
\text { Alcoholic cirrhosis } \\
\text { Hep C cirrhosis } \\
\text { CPC }\end{array}$ & $\begin{array}{l}\text { Decreased } \\
\text { Increased } \\
\text { No change } \\
\text { No change } \\
\text { Decreased } \\
70 \% \text { decreased expression }\end{array}$ & $\begin{array}{l}75 \\
75 \\
76 \\
12 \\
12 \\
73\end{array}$ \\
\hline & MRP3 & $\begin{array}{l}\text { NASH } \\
\text { Alcoholic cirrhosis }\end{array}$ & $\begin{array}{l}\text { Increased } \\
32 \% \text { increased expression }\end{array}$ & $\begin{array}{l}75 \\
12\end{array}$ \\
\hline & MRP4 & $\begin{array}{l}\mathrm{CPC} \\
\text { Primary biliary cholangitis }\end{array}$ & $\begin{array}{l}\text { Increased } \\
2.9 \text {-fold higher expression }\end{array}$ & $\begin{array}{l}73 \\
73\end{array}$ \\
\hline & NTCP & $\begin{array}{l}\text { PBC } \\
\text { Hep C cirrhosis } \\
\text { CPC }\end{array}$ & $\begin{array}{l}\text { Decreased } \\
36 \% \text { decreased expression } \\
34 \% \text { decreased expression }\end{array}$ & $\begin{array}{l}76 \\
12 \\
73\end{array}$ \\
\hline & BSEP & $\begin{array}{l}\text { PBC } \\
\text { Hep C cirrhosis }\end{array}$ & $\begin{array}{l}\text { No change } \\
\text { Decreased }\end{array}$ & $\begin{array}{l}76 \\
12\end{array}$ \\
\hline & MDR1 & $\mathrm{PBC}$ & Increased & 76 \\
\hline & MDR3 & PBC & Increased & 76 \\
\hline & P-gp & $\begin{array}{l}\mathrm{HCV} \\
\text { Alcoholic cirrhosis } \\
\text { Hep C Cirrhosis } \\
\text { CPC }\end{array}$ & $\begin{array}{l}\text { Increased } \\
\text { No change } \\
\text { Decreased } \\
\text { 2. } 6 \text {-fold higher expression }\end{array}$ & $\begin{array}{l}75 \\
12 \\
12 \\
73\end{array}$ \\
\hline & MATE1 & $\begin{array}{l}\text { Alcoholic cirrhosis } \\
\text { Hep C cirrhosis }\end{array}$ & $\begin{array}{l}\text { No change } \\
\text { Increased }\end{array}$ & 12 \\
\hline
\end{tabular}

